\title{
Nailfold capillary microscopy in connective tissue disease: a quantitative morphological analysis
}

\author{
F LEFFORD 1 AND J C W EDWARDS
}

From the Departments of ${ }^{1}$ Anatomy and ${ }^{2}$ Rheumatology, University College Hospital, London

SUMMARY Photomicrographs were taken of front line nailfold capillary loops in 18 healthy women (controls) and 42 women with established connective tissue disease (14 rheumatoid arthritis, 19 systemic lupus erythematosus, nine scleroderma). Measurements were made of apex width, maximum limb and loop widths, capillary length, interpeak distance, and frequency per linear millimetre. A numerical index for assessing capillary dilatation was derived, based on the mean of the apex plus maximum limb widths. Results show considerable overlap in subject means. Statistical analysis showed no difference between rheumatoid arthritis and control groups. Patients with systemic lupus erythematosus had slightly larger loops at a lower frequency (not statistically significant); three patients with an abnormal capillary index also had high titres of ribonucleoprotein antibody. Six scleroderma patients had abnormal indices, two of whom had high titre ribonucleoprotein antibody. No relation between capillary morphology and clinical features was found.

Key words: photomicroscopy, microcirculation, collagen diseases.

Capillary microscopy is a simple non-invasive method for examining the microcirculation in the living subject, both in health and disease. ${ }^{12}$ Accessible sites include the skin, lips, scleral conjunctiva, and the finger nailfold. The latter is most convenient for routine microscopical examination and is also a common site for macroscopically observable vascular lesions in connective tissue disease.

Histopathological appearances of biopsy and autopsy samples from patients with connective tissue disease show a range of inflammatory, destructive, and fibrotic changes affecting small blood vessels. Implication of the microvasculature in the pathophysiology of connective tissue disease is suggested by reports of abnormal capillary (exchange vessel) function. ${ }^{34}$ The finding of recognisably abnormal patterns in the nailfold capillary bed of patients with 'scleroderma spectrum disorders'5 has offered the prospect of this being a valuable ancillary investigation for patients suspected of having a connective tissue disease, with regard to: (a) defining the precise pattern of pathology; $(b)$ predicting outcome and monitoring the progress of the disease and the response to treatment.

Accepted for publication 3 March 1986.

Correspondence to Dr F Lefford, Department of Anatomy, University College London, Gower Street, London WC1E 6BT.
Maricq and coworkers reported real time observations in vivo and an analysis of capillary photomicrographs. $^{26}$ In common with other groups, ${ }^{78}$ however, they have presented their findings in the form of semiquantitative rating scales for the degree of capillary abnormality. It is difficult to apply such subjective criteria to other centres even if they are reliably consistent within the originating group.

Quantitative data are limited, and the capillary dimensions selected for measurements vary from group to group. ${ }^{9-11}$ Rheumatologists and dermatologists need a simple quantitative measurement of capillary morphology in order to compare and possibly pool data from different clinical centres. With these considerations in mind a quantitative analysis of nailfold capillaries with photomicroscopy has been undertaken on a group of healthy controls and a group of patients with connective tissue disease.

\section{Patients and methods}

S U B J E C T S

In view of the preponderance of female patients with connective tissue disease only female subjects were taken. The control group consisted of 18 

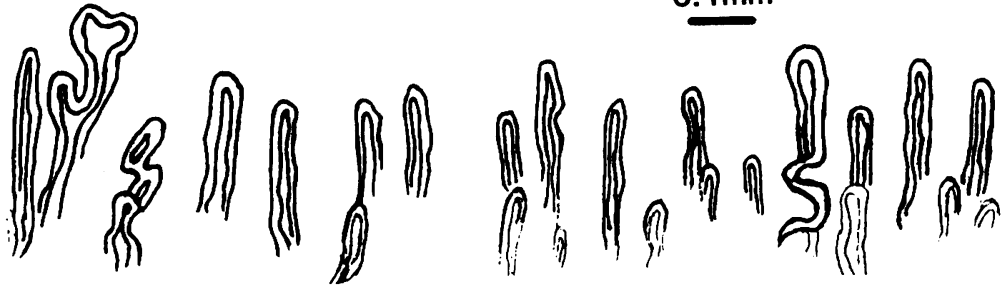

Fig. 1 Copy of a traced montage of front line nailfold capillary loops from projected negatives (control subject). healthy, symptom free hospital personnel: age range 22-58 years, mean 33 years. The group with connective tissue disease comprised a total of 42 patients routinely attending the Department of Rheumatology outpatient clinic at University College Hospital: 14 patients had classical or definite rheumatoid arthritis (RA) on American Rheumatism Association (ARA) criteria (age range 29-72 years, mean 55 years); 19 had systemic lupus erythematosus (SLE) on ARA criteria (age range 21-63 years, mean 38 years); and six had scleroderma (age range 30-64 years, mean 50 years). The last group included all patients attending the rheumatology clinic with hardening and thickening of the skin as described by Rodnan and Jablonska. ${ }^{12}$ Full clinical details are given in Table 4.

\section{PROCEDURE}

Fifteen to 30 minutes after arrival in the clinic subjects were taken to an enclosed side room with a steady ambient temperature of $20-23^{\circ} \mathrm{C}$. An electronic skin thermometer (Portec) with thermocouple sensor was attached to the dorsum of the fourth (ring) finger of the subject's left hand, which was then placed on the microscope stage at approximately heart level. The ring finger was chosen because it tends to be less traumatised and has a 3-5 $\mathrm{mm}$ length of proximal nailfold. When the ring finger capillaries were grossly abnormal or difficult to focus because of tissue thickening the middle (third) or little (fifth) finger nailfolds, or both, were photographed.

For examination the digit rested in a simple plastic mould and the proximal nailfold skin was covered with liquid paraffin to render the epidermis transparent. The capillaries were observed at $50 \times$ magnification ( $4 \times$ objective lens) with a binocular research microscope (Olympus 'Vanox') and a fibre optic quartz halogen light source. A series of photomicrographs of the front row capillary loops was taken (Olympus OM2N camera plus dedicated flash unit with a Wratten green filter (No 58)), starting at one end of the proximal nailfold and working across, with overlap of adjacent fields of view. Several frames of each field were taken at different planes of focus when adjacent capillary loops lay at varying depths within the nailfold. The procedure took 15-30 minutes for each subject.

Black and white $35 \mathrm{~mm}$ film (Ilford FP4, 125ASA) was used and developed under standard or conditions to give maximum contrast (D-76 at $20^{\circ} \mathrm{C}$ for eight minutes). Negative magnification was $\doteq$ $16.5 \times$, a compromise between depth of field and 0 size of image. Each roll of film was calibrated by including a photograph of a $1 \mathrm{~mm}$ stage micrometer. $\omega$ Subjects were taken at random and the negatives $\frac{\mathbb{O}}{0}$ coded sequentially for each individual. Numerical $\stackrel{\mathbb{D}}{3}$ coding ensured that subsequent analysis of the $\overline{0}$ negatives was performed blind with respect to $\stackrel{\mathbb{}}{-}$
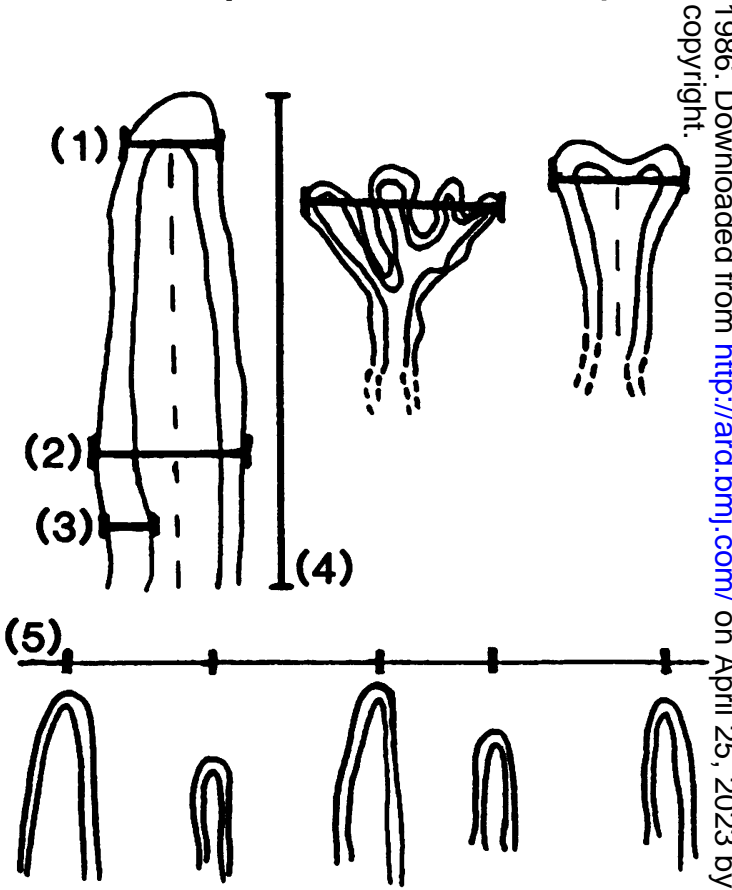

Fig. 2 Diagram of measurements made on front line nailfold capillary loops. From projected negatives: (1) apex width, (2) maximum loop width, (3) maximum limb width. From traced montage: (4) capillary length, (5) interpeak distance between capillary apices. 
control/patient groups and the disease category of the patients.

\section{A NALYS IS}

Negatives were projected on to tracing paper at $120 \times$ the original image. The most clearly focused image of each capillary loop was traced from consecutive negative frames; in this way a montage of the front line nailfold capillary loops was constructed (Fig. 1). An array of 11 clearly defined consecutive capillary loops in the mid-zone of the nailfold was selected and then projected. Measurements of apex width, maximum loop width, and maximum limb width (Fig. 2) were made directly from the focused images. The tracings were used to measure the frequency per linear millimetre, interpeak distances, and length of the capillary loops.

Gross capillary abnormality made it impossible to satisfy the selection criteria of a measurable array of vessels in two of the nine scleroderma patients, who were therefore excluded from subsequent numerical analysis. Of the seven remaining patients, it was necessary to select capillary loops from the middle finger in two and the little finger in three.

\section{SEROLOGICAL INVESTIGATIONS}

The following serological investigations were performed on all subjects with SLE or scleroderma: Rose-Waaler, antinuclear factor, DNA binding (Amersham kit, modified Farr assay), antibodies to extractable nuclear antigens including ribonucleoprotein (RNP), Sm, Ro, and La, and clotting studies for lupus anticoagulant (on the basis of prolongation of the partial thromboplastin time with kaolin without correction on mixing with normal plasma).

\section{Results}

For each subject the measurements made on the array of 11 selected capillary loops were averaged, giving a mean value per subject for any one variable.

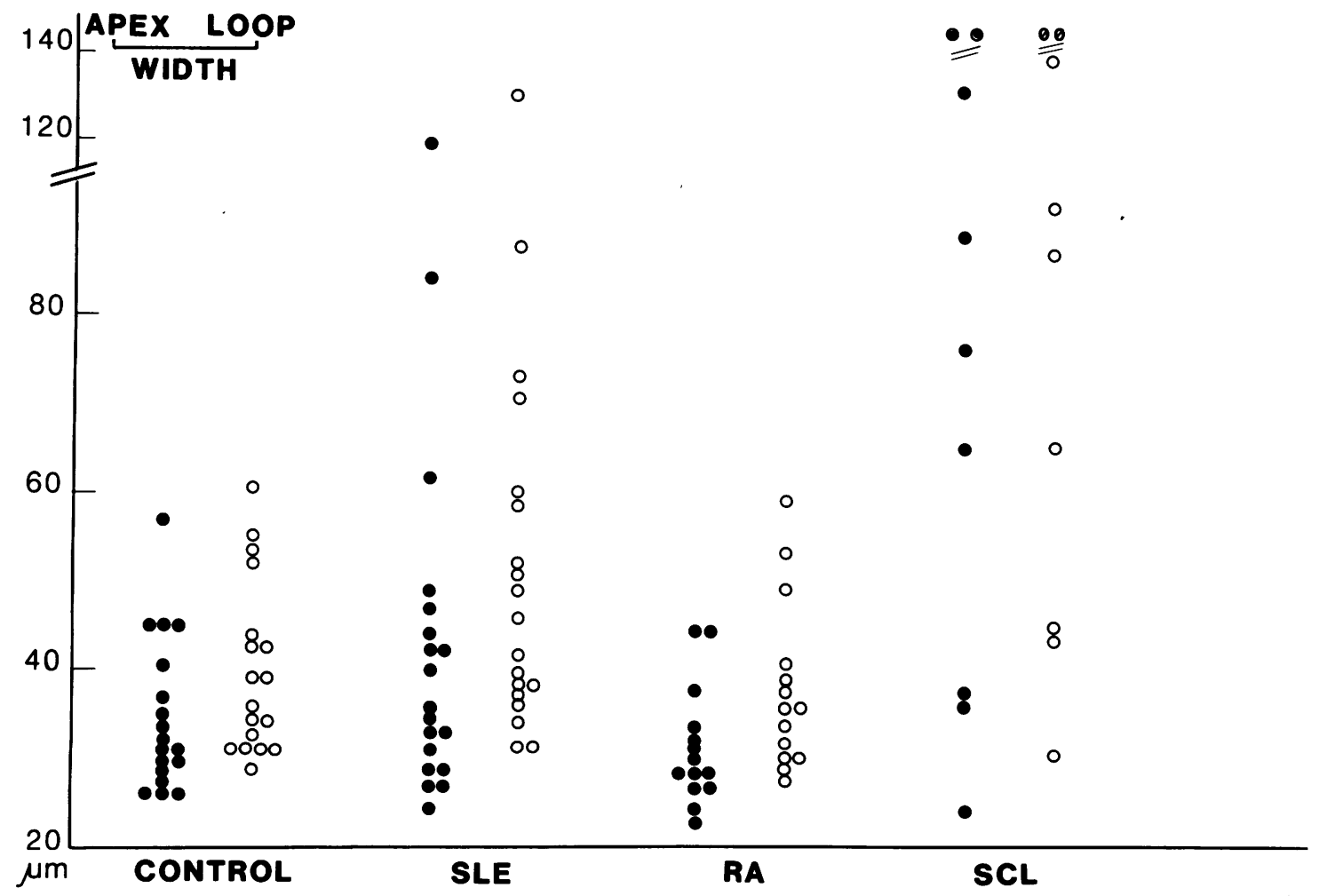

Fig. 3 Apex width (O) and maximum loop width (O) subject means. Figs 3, 4, 5, and 7 are scatter diagrams of data. Each point is the mean of the observations made on an individual subject. $R A=$ rheumatoid arthritis; $S L E=$ systemic lupus erythematosus; $S C L=$ scleroderma. The two scleroderma patients with grossly abnormal capillaries that were not measured are indicated by the symbols above the slash marks (II). 


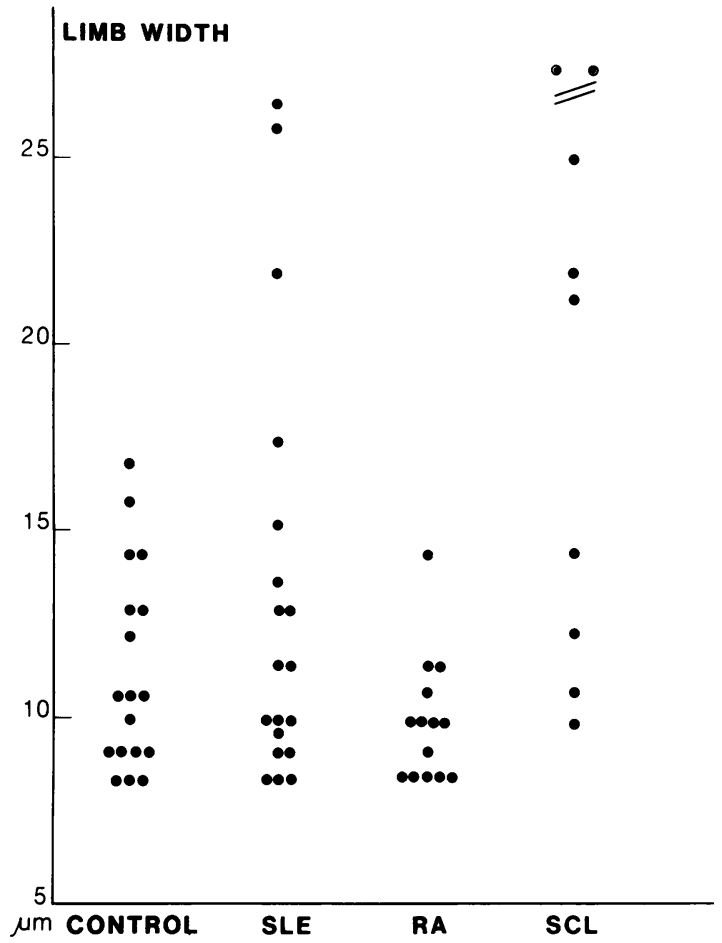

Fig. 4 Maximum limb width. (Further details given in Fig. 3 caption.)
APEX WIDTH ; LOOP WIDTH ; LIMB WIDTH These dimensions relate to the same variable, $\frac{\square}{\omega}$. namely the calibre of the capillary loop as measured by the width of the erythrocyte column visualised $\vec{\omega}$ within it. Despite considerable overlap between theo groups (Figs 3 and 4) three of the patients with음 systemic lupus erythematosus (SLE) had mean $\overline{\bar{w}}$ values consistently higher than the range for nor- $\overrightarrow{\mathbb{D}}$ mals for all dimensions. Four of the scleroderma patients had high apex and loop width means, but ${ }^{\mathrm{s}}$ only three of this group were beyond the control? range in limb width.

The two dimensional character of photomicroscopy makes the apex and limb widths more reliable@ measurements of capillary morphology than the? maximum loop width. A simple quantitative limb cr index based on the mean of the apex and maximum limb widths (Fig. 5) showed that the three SLE $\doteq$ patients and four scleroderma patients previouslyo referred to had values greater than the control group mean +3 SD $(38.9 \mu \mathrm{m})$. If $40 \mu \mathrm{m}$ was taken as the $\vec{c}$ upper limit of the normal range these patients could $\mathbb{8}$ be defined on quantitative grounds as having abnor- $\overrightarrow{\mathbb{D}}$ mally enlarged capillary loops. The paradox of the apparent normality of the other scleroderma $\stackrel{\Phi}{-}$ patients will be discussed later.

The group data are summarised in Table 1; the group mean is derived from the sum of the individual means (based on measurements of capillary loops). There was a consistent trend of

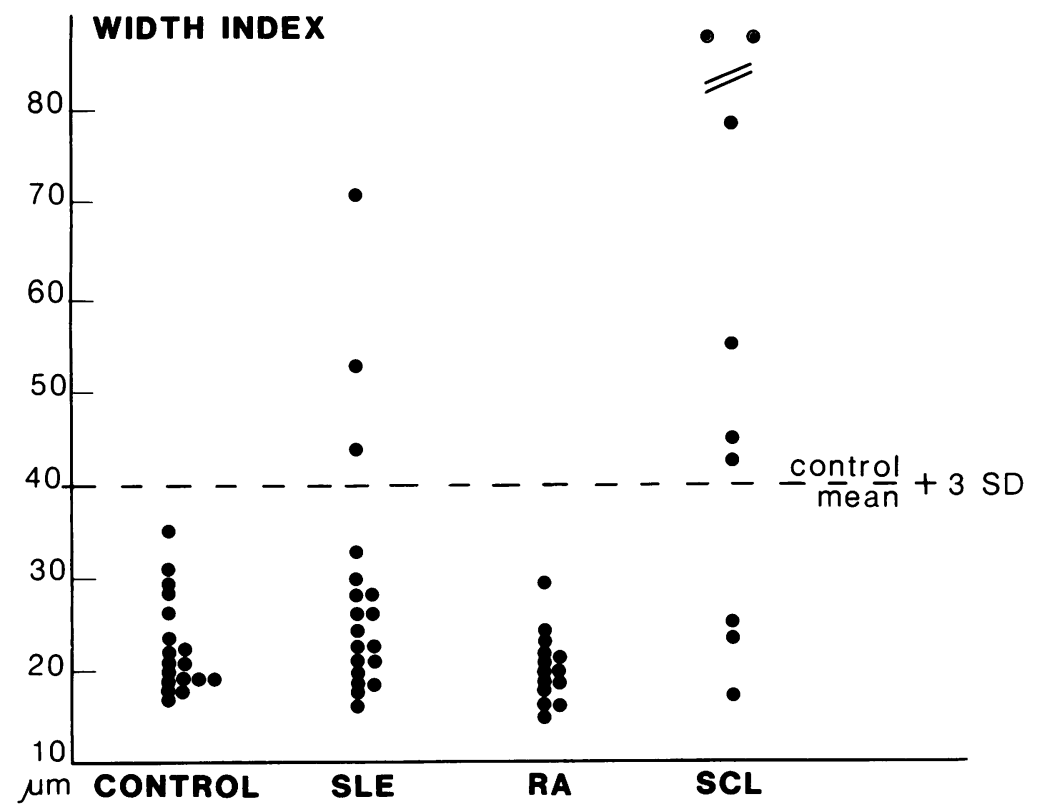

Fig. 5 Capillary width index (=mean of apex width + maximum 음 limb width). (Further details given in Fig. 3 caption.) 
Table 1 Summary of group data: group means (between subject standard deviation, $S D$ ) and within subject $S D$, in micrometres

\begin{tabular}{|c|c|c|c|c|}
\hline & $\begin{array}{l}\text { Group } \\
\text { mean }(S D)\end{array}$ & $\begin{array}{l}\text { Within } \\
\text { subject } S D\end{array}$ & $\begin{array}{l}\text { Group } \\
\text { mean }(S D)\end{array}$ & $\begin{array}{l}\text { Within } \\
\text { subject } S D\end{array}$ \\
\hline & \multicolumn{2}{|l|}{ Apex width } & \multicolumn{2}{|l|}{ Loop width } \\
\hline Control $(n=18)$ & $34.3(8.9)$ & $13 \cdot 0$ & $39.8(9.6)$ & $12 \cdot 9$ \\
\hline RA $(n=14)$ & $30 \cdot 7(7 \cdot 2)$ & $11 \cdot 6$ & $37.9(9 \cdot 7)$ & $14 \cdot 3$ \\
\hline SLE $(n=19)$ & $43.9(22 \cdot 6)$ & $27 \cdot 7$ & $52.9(24 \cdot 7)$ & $28 \cdot 6$ \\
\hline \multirow[t]{2}{*}{ SCL $(n=7)$} & $65.9(37.9)$ & $27 \cdot 6$ & $74 \cdot 6(43 \cdot 2)$ & $33 \cdot 6$ \\
\hline & \multicolumn{2}{|l|}{ Limb width } & \multicolumn{2}{|l|}{ Loop length } \\
\hline Control $(n=18)$ & $10.9(2.7)$ & 3.9 & $146 \cdot 3(54 \cdot 7)$ & 47.9 \\
\hline $\operatorname{RA}(n=14)$ & $9.9(1 \cdot 7)$ & $3 \cdot 0$ & $156 \cdot 3(49 \cdot 3)$ & $58 \cdot 6$ \\
\hline SLE $(n=19)$ & $13.2(5 \cdot 7)$ & $7 \cdot 3$ & $155 \cdot 6(72 \cdot 1)$ & $54 \cdot 8$ \\
\hline \multirow[t]{2}{*}{$\operatorname{SCL}(n=7)$} & $16 \cdot 5(6 \cdot 0)$ & $6 \cdot 5$ & $133.7(39 \cdot 5)$ & $52 \cdot 1$ \\
\hline & \multicolumn{2}{|c|}{ Interpeak distance } & \multicolumn{2}{|c|}{ Loops/linear millimetre } \\
\hline Control $(n=18)$ & $142 \cdot 2(26 \cdot 0)$ & $56 \cdot 7$ & $7.9(1.7)$ & \\
\hline $\operatorname{RA}(n=14)$ & $138.9(26.4)$ & $52 \cdot 5$ & $8 \cdot 1(1 \cdot 4)$ & \\
\hline SLE $(n=19)$ & $157.5(38 \cdot 1)$ & $56 \cdot 4$ & $7 \cdot 1(1.5)$ & \\
\hline SCL $(n=7)$ & $193.9(65.2)$ & $73 \cdot 2$ & $6.2(1.6)$ & \\
\hline
\end{tabular}

$\mathrm{RA}=$ rheumatoid arthritis; $\mathrm{SLE}=$ systemic lupus erythematosus; $\mathrm{SCL}=$ scleroderma .

increasing apex, loop, and limb widths in the SLE and scleroderma groups compared with the control group means, and increased variability both between and within individuals. Values for the rheumatoid arthritis (RA) group were similar to those of the controls. Kruskal-Wallis analysis of variance by ranks showed significant differences for all three measurements between groups (apex: $H=10 \cdot 20, p=0.017$; loop: $H=11 \cdot 26, p=0.011$; width: $H=9.47, p=0.024)$. The non-parametric Mann-Whitney $U$ test showed the scleroderma group measurements were significantly greater than those of the controls (Table 2). There was no significant difference between the control and SLE groups, but the values for the RA group were significantly less than those for the two other connective tissue disease groups. The variation within subjects for each group (within subject SD, Table 1) was noticeably higher for patients with SLE and scleroderma.
CAPILLARY LOOP LENGTH

The apparent loop length in the photographic image is determined by the obliquity of the angle at which the loop apex approaches the skin surface. Focus is lost at the loop base, giving a poorly defined cut off point. This measurement has therefore not been analysed statistically. The shorter loop length for the scleroderma group (Table 1) was consistent with the subjective impression of broad dilated loops seen in this condition (Fig. 6) and contrasted with the tendency for increased loop length in the SLE and RA groups.

\section{INTERPEAK DISTANCE; CAPILLARY FREQUEN C Y}

Predictably the group mean value for capillary frequency (loops per linear millimetre) was inversely related to the interpeak distance, which measures the linear separation between capillary loop apices (Table 1; Fig 7). The degree of variation

Table 2 Outcome of Mann-Whitney $U$ test for comparing non-parametric variables ( $p$ values on two-tailed tests), based on subject means

\begin{tabular}{|c|c|c|c|c|c|c|}
\hline \multirow[b]{2}{*}{ Scleroderma } & \multicolumn{2}{|c|}{ Apex width } & \multicolumn{2}{|c|}{ Loop width } & \multicolumn{2}{|c|}{ Limb width } \\
\hline & $\begin{array}{l}>\mathrm{C} \\
>\mathrm{RA}\end{array}$ & $\begin{array}{l}\mathrm{p}<0.04 \\
\mathrm{p}<0.02\end{array}$ & $\begin{array}{l}>\mathrm{C} \\
>\mathrm{RA}\end{array}$ & $\begin{array}{l}p=0.02 \\
p<0.02\end{array}$ & $\begin{array}{l}>\mathrm{C} \\
>\mathrm{RA}\end{array}$ & $\begin{array}{l}p<0.04 \\
p=0.002\end{array}$ \\
\hline SLE & $\begin{array}{l}\equiv \mathrm{C} \\
>\mathrm{RA}\end{array}$ & $\begin{array}{l}p>0.05 \\
p<0.02\end{array}$ & $\begin{array}{l}\equiv \mathrm{C} \\
>\mathrm{RA}\end{array}$ & $\begin{array}{l}p>0.05 \\
p<0.02\end{array}$ & $\begin{array}{l}\equiv \mathrm{C} \\
\equiv \mathrm{RA}\end{array}$ & $\begin{array}{l}p>0.05 \\
p>0.05\end{array}$ \\
\hline
\end{tabular}

$\mathrm{SLE}=$ Systemic lupus erythematosus; $\mathrm{C}=$ control; $\mathrm{RA}=\mathrm{Rheumatoid}$ arthritis.

Scleroderma $\equiv$ SLE for all variables $(p>0 \cdot 05)$; $C \equiv$ RA for all variables $(p>0.05)$. 


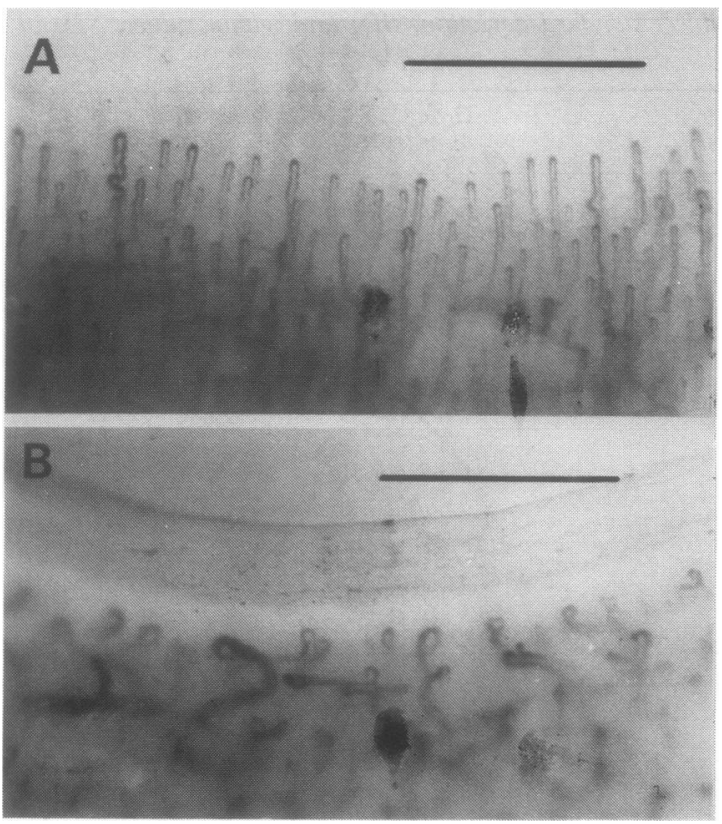

Fig. 6 Photomicrographs of nailfold capillary bed. $A=$ healthy control; $B=$ scleroderma patient with abnormal capillary index. Bar $=1 \mathrm{~mm}$.

in interpeak distance was higher for the scleroderma subjects than for the other groups. The RA and control groups means were similar, but the trend in SLE and scleroderma was for fewer capillaries, lying further apart. The Kruskal-Wallis test for analysis of variance was not significant for either observation (interpeak distance: $\mathrm{H}=7 \cdot 14, \mathrm{p}=0.07$; capillary frequency: $\mathrm{H}=700, \mathrm{p}=0.07)$. When the control and scleroderma groups were considered alone there was a significant difference: capillary frequency of

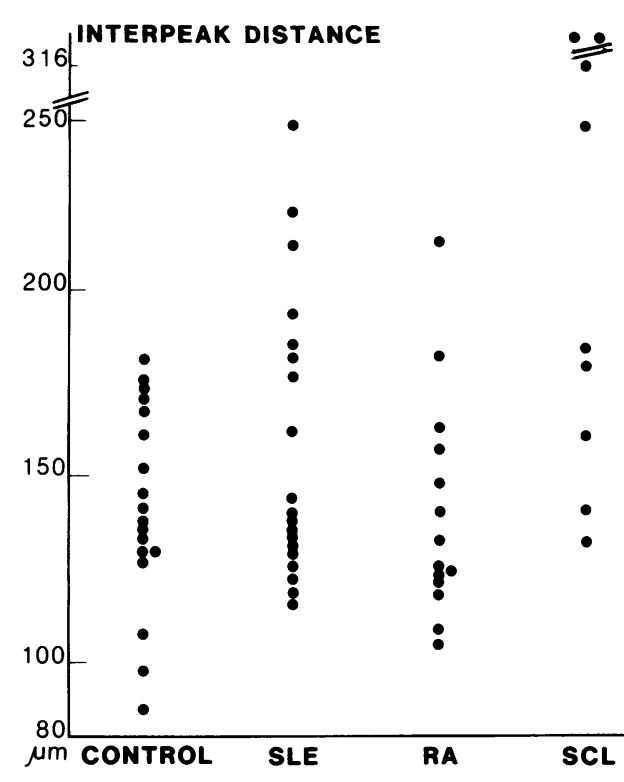

Fig. 7 Interpeak distance between capillary apices. (Further details given in Fig. 3 caption.)

controls greater than the scleroderma group $\mathrm{p}=0.03$ (one tailed); interpeak capillary distance $\overline{0}$ controls less than scleroderma, $\mathrm{p}=0.03$ (two tailed).

Linear discriminant analysis was performed based on all the variables measured. It confirmed that the apex width is the major factor discriminating between groups. The discriminant function separated $\overline{\overrightarrow{0}}$ out 10 SLE patients (including the three with an abnormal capillary index) and the same four scleroderma patients with abnormal capillary measurements.

Table 3 Clinical details of SLE patients

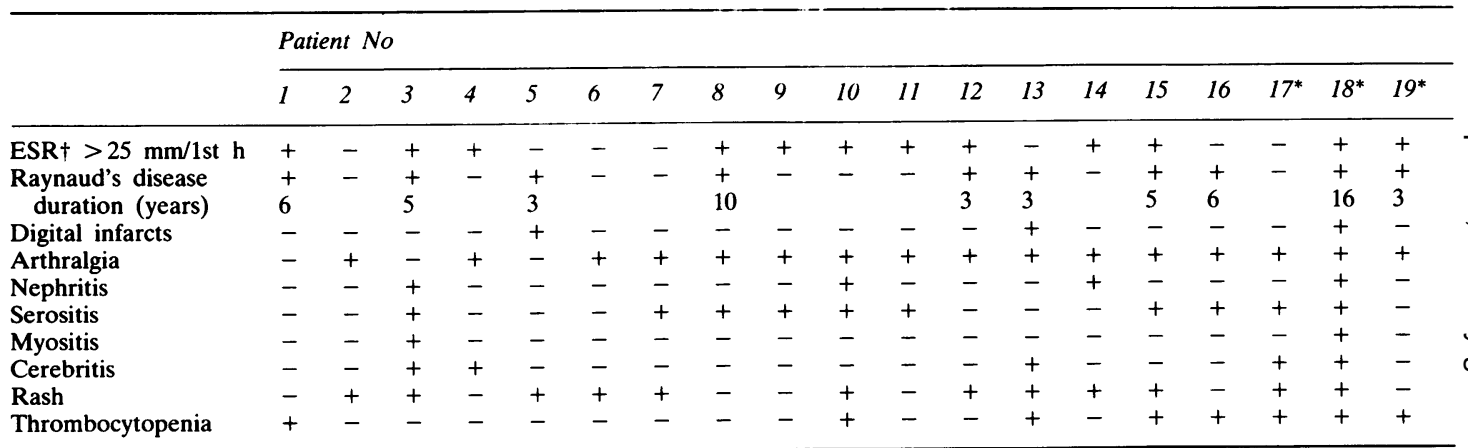

${ }^{*}$ Abnormal capillaries.

†ESR=erythrocyte sedimentation rate. 
RELATION TO CLINICAL FINDINGS

Within diagnostic groups individual clinical features were compared with nailfold capillary measurements and results of the linear discriminant analysis. Since measurements within the rheumatoid arthritis group were normal no further analysis was performed. Detailed clinical features of subjects in the SLE and scleroderma groups are given in Tables 3 and 4 . No relation between clinical findings and quantitative capillary abnormality could be found. Abnormal capillary morphology did not relate to disease duration in either the SLE or scleroderma groups.

Table 4 Clinical details of scleroderma patients

\begin{tabular}{llllllllllll}
\hline \multicolumn{1}{c}{ Patient } & No & & & & & & \\
\cline { 2 - 9 } & $1^{*}$ & 2 & $3^{*}$ & 4 & 5 & $6^{*}$ & $7^{*}$ & $8^{*}$ & $9^{*}$ \\
\hline ESR $>$ 25 mm/1st & $\mathrm{h}$ & - & - & + & + & - & - & - & + & - \\
Raynaud's disease & + & + & + & + & + & + & + & + & + \\
$\quad$ duration (years) & 14 & 4 & 5 & 8 & 5 & 18 & 13 & 18 & 5 \\
Digital ischaemia & - & - & - & - & + & - & - & + & - \\
Sclerodactyly alone & + & - & - & + & + & + & + & - & - \\
Acrosclerosis & - & + & + & - & - & - & - & + & + \\
Truncal scleroderma & - & - & + & - & - & - & - & + & + \\
Telangiectasia & + & + & - & - & + & + & - & + & + \\
Calcinosis & + & - & - & - & + & - & - & + & - \\
Pulmonary disease & - & + & - & - & + & - & + & - & + \\
Renal disease & - & - & - & - & - & - & - & - & + \\
Gut hypomotility & + & - & + & + & - & + & + & + & + \\
\hline
\end{tabular}

*Abnormal capillaries.
RELATION TO SEROLOGICAL FINDINGS

A detailed serological assessment was made on subjects with SLE and scleroderma. This was not extended to the rheumatoid arthritis group, for whom serology was limited to the Rose-Waaler test (positive in all cases). Serological findings are given in Tables 5 and 6; titres are the highest recorded within a year of the nailfold examination. Within the SLE group an abnormal capillary width index was associated in all cases with antibodies to RNP. The incidence of antibodies to RNP in the other SLE subjects was four in 16 . Other specific antibodies did not correlate with nailfold capillary abnormality.

Within the scleroderma group no significant relation between serological findings and capillary morphology was observed.

\section{Discussion}

OBSERVATIONS ON THE CONTROL HEALTHY POPULATION

Our results tend to fall at the lower end of the range recorded by others when similar measurements have been taken (Table 7). The discrepancy for maximum limb width may be due to our measuring the most sharply focused image closer to the loop apex. Differences in capillary frequency arise from ambiguity in defining front line nailfold capillary loops from overlapping vessels in adjacent dermal papillae. ${ }^{13}$ The subjective element in measuring loop length ${ }^{9}$ is shown by the variation in values.

Table 5 Serological features of SLE patients

\begin{tabular}{|c|c|c|c|c|c|c|c|}
\hline $\begin{array}{l}\text { Patient } \\
\text { No }\end{array}$ & $\begin{array}{l}\text { ANA } \\
\text { titre }\end{array}$ & $\begin{array}{l}\text { Rose-Waaler } \\
\text { titre }\end{array}$ & $\begin{array}{l}\text { Positive } \\
\text { DNA } \\
\text { binding }\end{array}$ & Anti-RNP & Anti-Sm & Anti-Ro & $\begin{array}{l}\text { Lupus } \\
\text { anticoagulant }\end{array}$ \\
\hline 1 & 80 & - & + & - & - & - & - \\
\hline 2 & 320 & - & - & - & - & - & - \\
\hline 3 & 10240 & - & + & + & + & - & - \\
\hline 4 & 640 & - & - & - & - & - & - \\
\hline 5 & 160 & - & - & - & - & - & - \\
\hline 6 & 160 & - & - & - & - & + & - \\
\hline 7 & 80 & - & - & - & - & - & - \\
\hline 8 & 320 & 320 & - & - & - & - & - \\
\hline 9 & 5120 & 5120 & + & + & + & - & - \\
\hline 10 & 2560 & - & + & - & - & - & + \\
\hline 11 & 2560 & 2560 & + & - & - & - & - \\
\hline 12 & 80 & - & - & - & - & + & - \\
\hline 13 & 2560 & - & - & + & - & - & + \\
\hline 14 & 80 & - & + & - & - & - & + \\
\hline 15 & 2560 & - & + & - & - & + & - \\
\hline 16 & 320 & - & - & - & - & - & - \\
\hline $17^{*}$ & 640 & - & + & + & - & - & - \\
\hline $18^{*}$ & 320 & - & + & + & - & + & - \\
\hline $19^{*}$ & 2560 & - & - & + & - & - & - \\
\hline
\end{tabular}

${ }^{*}$ Abnormal capillaries. 
Table 6 Serological features of scleroderma patients

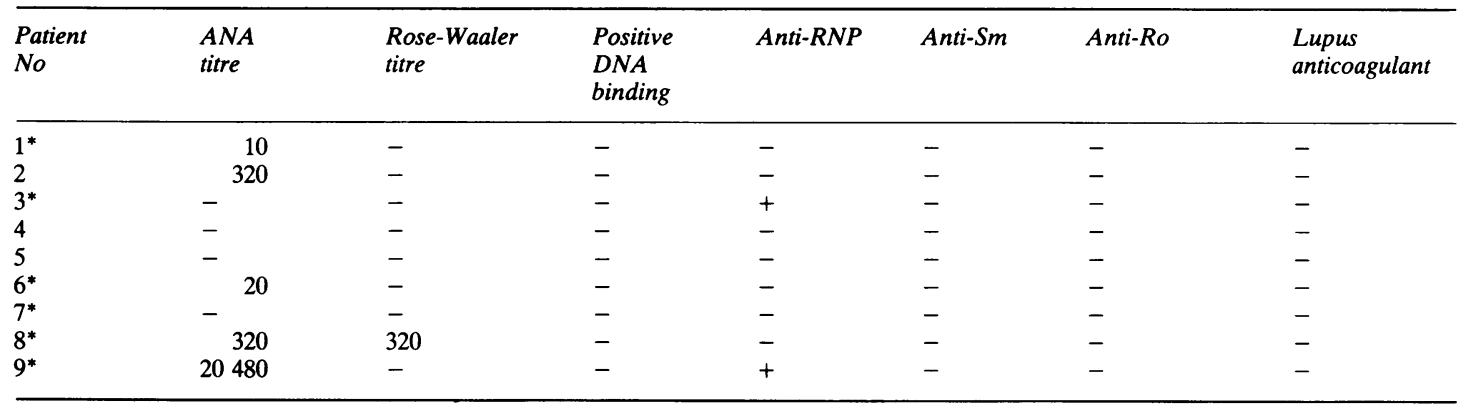

*Abnormal capillaries.

Table 7 Results of this study and comparable quantitative data of other groups

\begin{tabular}{|c|c|c|c|c|c|c|c|c|c|}
\hline & \multicolumn{2}{|c|}{ Apex width $(\mu \mathrm{m})$} & \multicolumn{2}{|c|}{ Limb width $(\mu m)$} & \multicolumn{2}{|c|}{ Loop length $(\mu \mathrm{m})$} & \multicolumn{3}{|c|}{$\begin{array}{l}\text { Capillaries/linear } \\
\text { millimetre }\end{array}$} \\
\hline & Mean $(S D)$ & Ref & Mean $(S D)$ & $\operatorname{Ref}$ & Mean $(S D)$ & $\operatorname{Ref}$ & Mean $(S D)$ & Ref & \\
\hline Control group & $\begin{array}{l}34(9)^{*} \\
30(7)\end{array}$ & 10 & $\begin{array}{c}11(3)^{*} \\
7-12 \\
12-30 \\
7-18 \\
11 \\
15(3)\end{array}$ & $\begin{array}{r}1 \\
7 \\
2 \\
13 \\
21\end{array}$ & $\begin{array}{l}146(55)^{*} \\
168(67) \\
200-400 \\
350\end{array}$ & $\begin{array}{r}10 \\
2 \\
20\end{array}$ & $\begin{array}{c}8(2)^{*} \\
10-20 \\
9(2) \\
7-17 \\
13(2)\end{array}$ & $\begin{array}{r}1 \\
10 \\
2 \\
13\end{array}$ & 음 \\
\hline Rheumatoid arthritis & $\begin{array}{l}31(7)^{*} \\
30(8)\end{array}$ & 10 & (no other da & & $\begin{array}{l}156(49)^{*} \\
207(74)\end{array}$ & 10 & $\begin{aligned} & 8(1)^{*} \\
& 10(2)\end{aligned}$ & 10 & $\stackrel{\overline{0}}{2}$ \\
\hline Systemic lupus erythematosus & - & & - & & $\begin{array}{l}156(72)^{*} \\
700\end{array}$ & 20 & - & & \\
\hline
\end{tabular}

${ }^{*}$ Results of this study. No comparable quantitative data for scleroderma.

Values are group means and standard deviation (SD), rounded up.

In addition to the quantitative evidence of normal variation in size and frequency of nailfold capillaries, irregularities of shape such as apex indentation, criss crossing, and undulation of limbs ${ }^{7}$ were often seen. Gross apex dilatation (telangiectasia) and capillary conglomerates ('bushy' capillaries ${ }^{2}$ ) were never seen. Haemorrhages within the cuticular epidermis, of traumatic origin, were a non-specific finding.

\section{OBSERVATIONS ON PATIENTS}

We have confirmed that the morphology of nailfold capillaries in rheumatoid arthritis patients is similar to normal ${ }^{814}$ despite evidence of abnormal microvascular filtration in the same patients investigated by us within a year of photomicroscopy. ${ }^{4}$ The small calibre of the nailfold capillary loops in rheumatoid arthritis patients is consistent with radiological observations. ${ }^{15}$ The significant differences in capillary morphology between RA patients and the
SLE/scleroderma groups suggest a different underlying microvascular pathophysiology.

The SLE group data indicate an overall enlargement and lower frequency of nailfold capillaries, but no specific abnormality was noted. ${ }^{2}$ A small group of three patients with wider calibre, broader loops emerge as having abnormal capillaries by the capillary limb index. We confirm no relation between capillary morphology and clinical features, ${ }^{8}$ including Raynaud's phenomenon. All three patients with abnormal capillaries had antibody to ribonucleoprotein. (None had lupus anticoagulant $\mathrm{N}$ or a positive Rose-Waaler test. One had antibodies $N$ to SSB.) This suggests that there may be a connection between the pathogenesis of capillary enlargement and the formation of ribonucleoprotein antibodies which is not necessarily reflected in the spectrum of clinical illness

The scleroderma group data provide quantitative confirmation of observations made by 
others. ${ }^{126911}$ The abnormal findings of the scleroderma group cannot be attributed to age in view of the normal data for the rheumatoid arthritis group, which has a similar mean age. The paradox of normal capillary indices in three of the nine scleroderma patients, despite overt disease, is the outcome of the stringent criteria applied to capillary selection. This has led to measurement of the most normal capillary loops, producing data that underestimate the differences between scleroderma patients and controls. We confirm the results of a recent study ${ }^{16}$ in finding no relation between nailfold capillary appearances and severity of disease, including organ involvement, though two of the six patients with abnormal capillary indices had ribonucleoprotein antibody. The value of capillary microscopy as an aid to prognosis in established disease $^{5}$ is therefore questionable.

The capillary limb index is a simple quantitative measurement of nailfold capillary morphology for use in an outpatient setting. Although capillary microscopy has been proposed as a diagnostic aid, ${ }^{17}$ the extensive overlap of indices between groups limits its value in establishing the diagnostic category of a patient with an equivocal connective tissue disease. The index provides an objective criterion, however, for defining the degree of (ab)normality of nailfold capillaries and allows quantitative assessment of changes with time. The latter is potentially the most informative with respect to individual patients for monitoring progress because of the dynamic state of the nailfold capillary bed in disease. ${ }^{18} 19$

We wish to thank Dr M L Snaith, Director of the Department of Rheumatology, University College Hospital and Dr B Zoob for access to their patients; also Mr B Newman, Department of Statistics, University College, London, for statistical advice and help. Photographic equipment was funded by a grant ( $\mathrm{Dr} F$ Lefford) from the Central Research Fund, University of London.

\section{References}

1 Davis E, Landau J. Clinical capillary microscopy. Springfield, Illinois: Thomas, 1966.

2 Maricq H R, Maize J C. Nailfold capillary abnormalities. Clin Rheum Dis 1982; 8: 455-78.
3 Marks J, Birkett D A, Shuster S. Capillary permeability in patients with collagen vascular disease. Br Med J 1972; i: 782-4.

4 Edwards J C W, Snaith M L. Microvascular filtration in subjects with connective tissue disorders. Ann Rheum Dis 1984; 43: 576-80.

5 Maricq H R, Leroy E C, D'Angelo W A, et al. Diagnostic potential of in vivo capillary microscopy in scleroderma and related disorders. Arthritis Rheum 1980; 23: 183-9.

6 Maricq H R. Widefield capillary microscopy. (Technique and rating scale for abnormalities seen in scleroderma and related disorders). Arthritis Rheum 1981; 24: 1159-65.

7 Redisch W, Messina E J, Hughes G, McEwen C. Capillaroscopic observations in rheumatic diseases. Ann Rheum Dis 1970; 29: 244-53.

8 Lee P, Leung F Y-K, Alderdice C, Armstrong S K. Nailfold capillary microscopy in the connective tissue diseases: a semiquantitative assessment. $J$ Rheumatol 1983; 10: 930-8.

9 Rouen L R, Terry E N, Doft B H, Clauss R H, Redisch W. Classification and measurement of surface microvessels in man. Microvasc Res 1972; 4: 285-92.

10 Zaric D, Worm A M, Stahl D, Clemmensen O J. Capillary microscopy of the nailfold in psoriatic and rheumatoid arthritis. Scand J Rheumatol 1981; 10: 249-52.

11 Buchanan I S, Humpston D J. Nailfold capillaries in connective tissue disorders. Lancet 1968; i: 845-7.

12 Rodnan G P, Jablonska S. Classification of systemic and localised scleroderma. In: Black C M, Myers A R, eds. Current topics in rheumatology: systemic sclerosis (scleroderma). New York, London: Gower Medical Publishing, 1985: 3-6. (American Rheumatism Association.)

13 Vayssairat M, Priollet P. Atlas pratique de capillaroscopie. Paris: Les Éditions de La Revue de Médecine, 1983.

14 Schumacher H R, Ligot P N, Parry P E. Conjunctival and nailfold microcirculation in patients with rheumatoid arthritis and normal subjects. Acta Rheumatol Scand 1968; 14: 253-64.

15 Laws J W, Willie J G, Scott J T. Arteriographic appearances in rheumatoid arthritis and other disorders. Br J Radiol 1963; 36: 477-93.

16 Lovy M, MacCarter D, Steigerwald J C. Relationship between nailfold capillary abnormalities and organ involvement in systemic sclerosis. Arthritis Rheum 1985; 28: 496-501.

17 Kenik J G, Maricq H R, Bole G G. Blind evaluation of the diagnostic specificity of nailfold capillary microscopy in the connective tissue diseases. Arthritis Rheum 1981; 24: 885-91.

18 Maricq H R. Microangiopathy in systemic scleroderma and related disorders. Int Angiol 1983; 2: 119-28.

19 Maricq H R. Nailfold biopsy in scleroderma and related disorders. Dermatologica 1984; 168: 73-7.

20 Vayssairat M, Priollet P, Goldberg J, Housset E. Nailfold capillary microscopy as a diagnostic tool and in follow-up examination. Arthritis Rheum 1982; 25: 597-8.

21 Bollinger A, Jager K, Roten A, Timeus C, Mahler F. Diffusion, pericapillary distribution and clearance of $\mathrm{Na}$-fluorescein in the human nailfold. Pflugers Arch 1979; 382: 137-43. 